elements of mind does not shake our conviction that all these are the results of cellular activity.

For us as physicians and in connexion with our present theme it is enough that no manifestation of mind can occur without cellular excitation and that such cells are portions of an organism which is one and indivisible however various the functions of its several organs. These cellular activities and persistent impressions are proper to all animal life and are capable of influencing the organism manifesting them for good or for evil. In the microcosm of man, however, we have to deal with a development of ideation as peculiar to him as the maintenance of the erect position. When Mephistopheles wrote in the album of the young student, "Eritis sicut Deus, scientes bonum et malum," that profound judge of human nature added as the awestruck boy withdrew, and with something as nearly approaching a sigh as his highness was capable of, "A weary man thy likeness to the gods will make of thee." This likeness to the gods, however indistinct at times that image may become, the physician has to bear in mind in every department of the healing art outside the sphere of veterinary medicine. Such stimuli by efferent channels act in promoting the health and life or disease and death of the viscera and of the body of which they are a part. Physical disorders, on the other hand, which impair the nutrition of the centres of vital force directly or indirectly produce similar results in various ways with varying rapidity and in varying measure.

How often, for example, do we encounter cases in practice in which the weariness of life causes the patient to desire death when the actual causes of disturbed health or happiness appear to us quite inadequate to account for so much distress. And, again, how frequently do we observe the desire to live to be strong in those the cessation of whose discomfort can only coincide with the termination of life. This despondency in some cases, this unquenchable hope of recovery on the brink of dissolution in others, as also the anxious or calm and heroic struggle for life in yet others, are noteworthy phenomena and reveal to us how complex a creature we have to deal with in man. Could we explain more fully the organic relations of the tredium viter, of the spes vivere, and of that magna quies-that grand repose manitested in face of the still greater quietude of death-we should have made a considerable advance in our knowledge of the relation of the nervous system to visceral disease and disorder. To a humble study of some such points in the pathology of visceral control and the clinical phenomena observed when such control is impaired I purpose devoting the remainder of this course of lectures appreciating full well the difficalty of the subject and also $\mathrm{my}$ own inability to do it jastice.

\section{GSOPHAGO-ENTEROSTOMY AFTER TOTAL EXTIRPATION OF THE STOMACH.}

BY DR. CARL SCHLATTER, ASSISTANT SURGEON IN THE SURGICAL CLINIC OF ZÜRICH,

Specially Translated for ThE LANCET.

For the title of the present paper I have selected the newly-coined expression "Wsophago-enterostomy," my reason being that the phrase "total extirpation of the stomach" as used in the most recent literature is not understood in the strict sense of the word and there is a danger that in the present case a part may be taken for the whole. The few cases which have hitherto been recorded in literature as instances of total resection of the stomach prove on closer examination not to be exactly as described, for without exception a small portion of the stomach, chiefly of the cardiac end, was left behind. Even in the case of the celebrated dog on which gastrectomy was performed by Czerny and Kaiser in 1876, and which so to say lived without a stomach for five years, it was found on post-mortem examination that a small portion of the cardiac end of the stomach wall still remained. I am in the happy position of being able to-day to refer to a patient on whom I have successfully performed an absolutely complete removal of the stornach and have restored the interrapted continuity of the digestive tract by uniting a loop of the small intestine to the end of the cesophagus.

The patient is a woman, fifty-six years of age; she is a silk-winder and has no family history of carcinoma. Even as a child she always suffered from pains in the stomach, since the food in the orphanage where she was brought up was very bad. In later years she frequently suffered from pain in the stomach and vomiting. She has vomited every day since Whitsuntide, 1897. There was bile in the romit, but blood was never found. The drugs prescribed by a medical man had no effect. Some weeks before she entered the hospital a second medical man was consulted, who recognised a tumour in the left side of the abdomen and recommended hospital treatment. I saw the patient for the first time on Aug. 26th, 1897, in the Surgical Poliklinik. When the abdomen was uncovered a prominence between the left margin of the thorax and the umbilicus immediately came into view. On palpation through the extremely relaxed abdominal walls there could be felt in the gastric region a hard tumour of an elongated oval form of about the size of two fists and remarkably moveable. The patient, who was emaciated to the utmost, complained that she vomited every kind of food alike, even milk, and wished to have an operation performed under any circumstances. I feared that with a tumour of this size resecticn of the stomach could not be accomplisbed and that it would be found that the condition of the walls of the stomach would not admit of gastro-enterostomy, but I admitted the patient into the surgical department for the sake of observation and inquiry. She vomited almost all liquid nourishment a short time after it was taken. (The iodide of potassium reaction in the saliva did not appear in less than forty-seven minates.) Examination of the gastric juice yielded no trace of free bydrochloric acid.

On Sept. 6th, acting as locum tenens for Professor Krönlein, I undertook an exploratory laparotomy in order to gain a more precise knowledge of the tumour and if possible also to decide the question of excision or gastro-enterostomy. Anæsthesia having been induced by morphia and ether I opened the peritoneal cavity with the most careful aseptic precautions by an incision in the linea alba extending from the ensiform process to the umbilicus. As I had feared from the results of the external examination the whole stomach, from the pylorus up to and including the cardiac portion, was converted into a singularly hard but quite moveable tumour which could be easily withdrawn from the peritoneal cavity. On the great curvature towards the pylorus there were three small lymph glands which were soft to the touch. I could not perform gastro-enterostomy because the entire stomach presented no healtby portion and nothing remained for me but either to attempt total resection or else to have recourse to jejunostomy. For obvious reasons I preferred the former alternative.

After shutting off the peritoneal cavity with sterilised compresses I isolated the stomach on its great and small curvatures, separating the great and the small omentum with the aid of Péan's clamps and ligaturing the clamped portions with silk. I then pulled it firmly downwards in order to obtain access to the cesophagus. The left lobe of the liver which covered the field of operation was held up constantly by the hand of an assistant, in which way we succeeded in applying a Wölfler's compressorium to the cesophagus tolerably high up. I applied a Stille's clamp quite close to the cardiac border of the tumour and separated the stomach from the cesophagus just at their point of junction. The direction of the incision happened to be somewhat oblique, so that I found it to be advantageous to reduce the aperture of the cesophagus by means of a small suture. The pylorus was treated in exactly the same way. The duodenum was freed as far as possible towards the head of the pancreas and the stomach together with the pylozus was separated between a "duodenum compressorium" applied as far away as possible and a "tumour compressorium" applied to the duodenal region. The aperture of the portion of the duodenum which remained in situ was cleansed with pads of jodoform gauze just as had been already done in the case of the aperture of the cesophagus. An extensive portion in the continuity of the digestive tract was now cut away. I endeavoured to draw up the end of the duodenum to the end of the cesophagus, but it was only with the greatest difficulty that I could bring them into contact, so that the union of the two orifices was not to be expected. I turned in the border of the doodenum and closed the apertore with a double"suture. 
Starting from the duodeno-jejunal fold I followed the small intestine downwards for about thirty centimetres (12 in.), drew it out at that point, brought it across the transverse colon, and applied it to the end of the cesophagas (see Fig. 1).

Frg. 1.

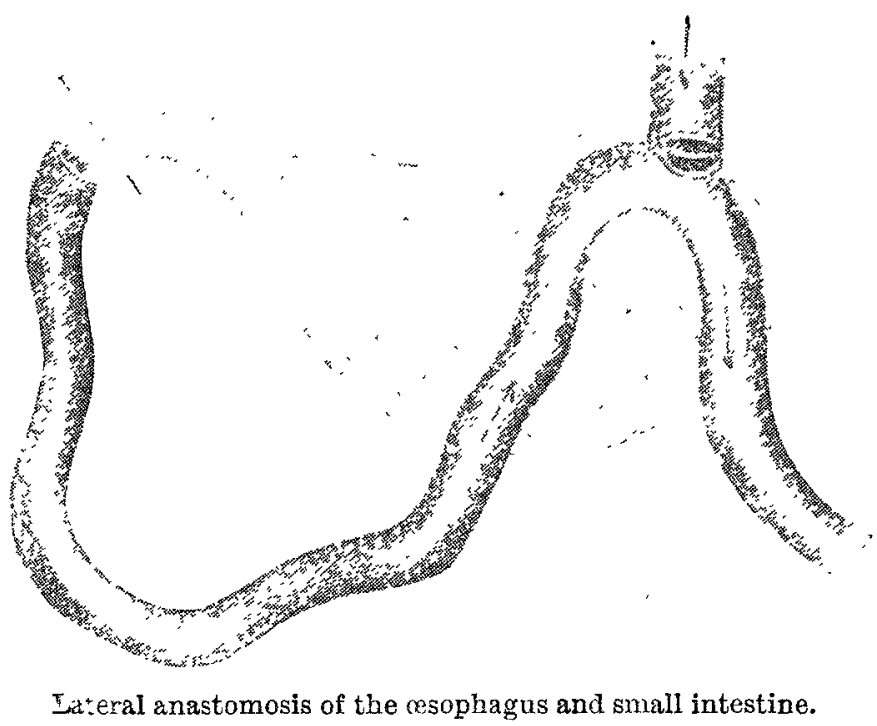

A piece of the small intestine about ten centimetres (4 in.) long being held in Wölfer's compressors the intestine was fixed to the oesophagas by suturing the serous membrane after which it was incised for about one and a half centimetres $(0.6$ in. $)$ in the direction of its length and the mucous membrane of the cesophageal part was nnited in its whole circumference with the mucous membrane of the intestine by means of a continuous circular silk suture. A suture of continuous muscular and serous tissue and a Lembert's interrupted silk suture were applied over the suture of the mucous tissue. The compressors on the small intestine as well as the one on the extremity of the cesophagus, which latter had been in position for more than two bours, were removed. When returned to the peritoneal cavity the sutured parts retracted themselves upwards with some force to the place where the cesophagus traverses the diaphragm. The abdominal walls were closed with continuous silk suturing of the peritoneum and interrupted silk suturing of the fascia and skin. The anrsthesia (230 c.c.-i.e., 8 fluid ounces-of ether) progressed quietly. The pulse after the operation was regular, tolerably full, and 96 per minute.

The excised stomach had on its great curvature a length of twenty-eight centimetres (11 in.) and on its small curva. ture a length of twenty centimetres ( $8 \mathrm{in}$.$) ; the greatest$ distance between the two curvatures amounted to ten centimetres (4in.). Its internal diameter was so extremely reduced that at either end a forefinger could only be inserted with diffculty. In order to obtain a decisive opinion as to the extent of the resection I cat off small portions from each end of the excised stomach, sent them to the Pathological Institute for examination, and received a report from Professor Ribbert as follows: "Of the specimens inquired about the one from the cardiac extremity is cesophagus and the other is dnodenum. The anatomical description of a portion taken from the tumour of the stomach was "smallcelled alveolar glandular carcinoma" ("klein alveoläres Drüsenzellencarcinoma"). The attached lymph glands were not carcinomatous.

Soon after the operation the patient was given an enema containing brandy and two eggs. Her evening temperature was $36.4^{\circ} \mathrm{C}$. $\left(976^{\circ} \mathrm{F}\right.$.). On Sept. 7th she had two nutritive enemata of milk, eggs, and brandy. The pulse was very rapid, being 142 per minute, but it was tolerably firm. The evening temperature was $37.3^{\circ} \mathrm{C} .\left(990^{\circ} \mathrm{F}\right.$.). Even as early as the afternoon of this day she had some tea and milk by the mouth and they were taken quite well. There were no symptoms of peritonitis. On Sept. 8th a half glass of Bordeaux was taken at mid-day by teaspoonfuls. The nutrient enemata were discontinued. In the evenith the temperature rose to $38^{\circ} 1^{\circ} \mathrm{C}$. $\left(100 \cdot 6^{\circ} \mathrm{F}\right.$.), the pulse also rose to 160 , remaining however tolerably firm. 'The patient complained of pains in the region of the stomach coming on suddenly and soon disappearing. On Sept. 9th the subjective conditions were much better. Pepsin and hyorochloric acid were added experimentally to the diet, which consisted of milk, eggs, soup, wine, \&c., taken in small quantities at intervals of two hours. The pulse was 146 and satisfactory. The highest temperature for the day was $38.1^{\circ} \mathrm{C}$. $\left(100^{\circ} 6^{\circ} \mathrm{F}_{\text {. }}\right)$. On Sept. 13th the dressings were changed for the first time. The wound was completely healed by primary union without reaction. The stitches were removed. The patient took some scraped meat to-day. The first action of the bowels after the operation took place on Sept. 10th, since which date the patient has had from two to three liquid evacuations daily. Now and then the milk which bad been taken was brought up, but without actual romiting. On Sept. 16th the patient felt herself very well in all respects. The temperature bad returned to the normal point; the pulse had fallen to about 100 ; there was slight diarrhœa. Her dietary was tolerably ample in amount, being as follows: Two decilitres (7 fluid ounces) of milk and an egg at 7 A.M. and again at $930 \mathrm{~A} . \mathrm{M}_{\text {. ; }}$ at mid.day some tender meat, scraped or minced, or a cup of gruel; at 4 P.M. a cup of gruel with an egg, or two decilitres of milk with an egg; at 7.30 P.M. a cap of milk or gruel. In the intervals she drank from 150 to 200 grammes (from 6 to 8 fluid ounces) of tea or Malaga in the course of the day. She vomited to-day for the first time as the result of a feeling of nausea occasioned by another patient in the ward having her dressings changed. She went through the forcible movements of romiting and brought up about 100 c.c. ( $3 \frac{1}{2}$ fluid ounces) of a bile-stained, faintly sour-smelling liquid.

On Sept. 26th she had half of a fowl at mid-day and ate all the remainder of it at 430 P.M. At 6.30. P.M. she took the usual allowance of milk with egg. At 7.30 P.M. she was sick, the abdominal muscles contracting powerfully and the act of romiting being energetic. She brought up about 300 c.c. ( $10 \frac{1}{2}$ tluid ounces) of liquid, the greater part of which evidently was the milk that had been taken an hour before, together with fibres of meat from the repast at 4.30 P.M

FIG. 2.

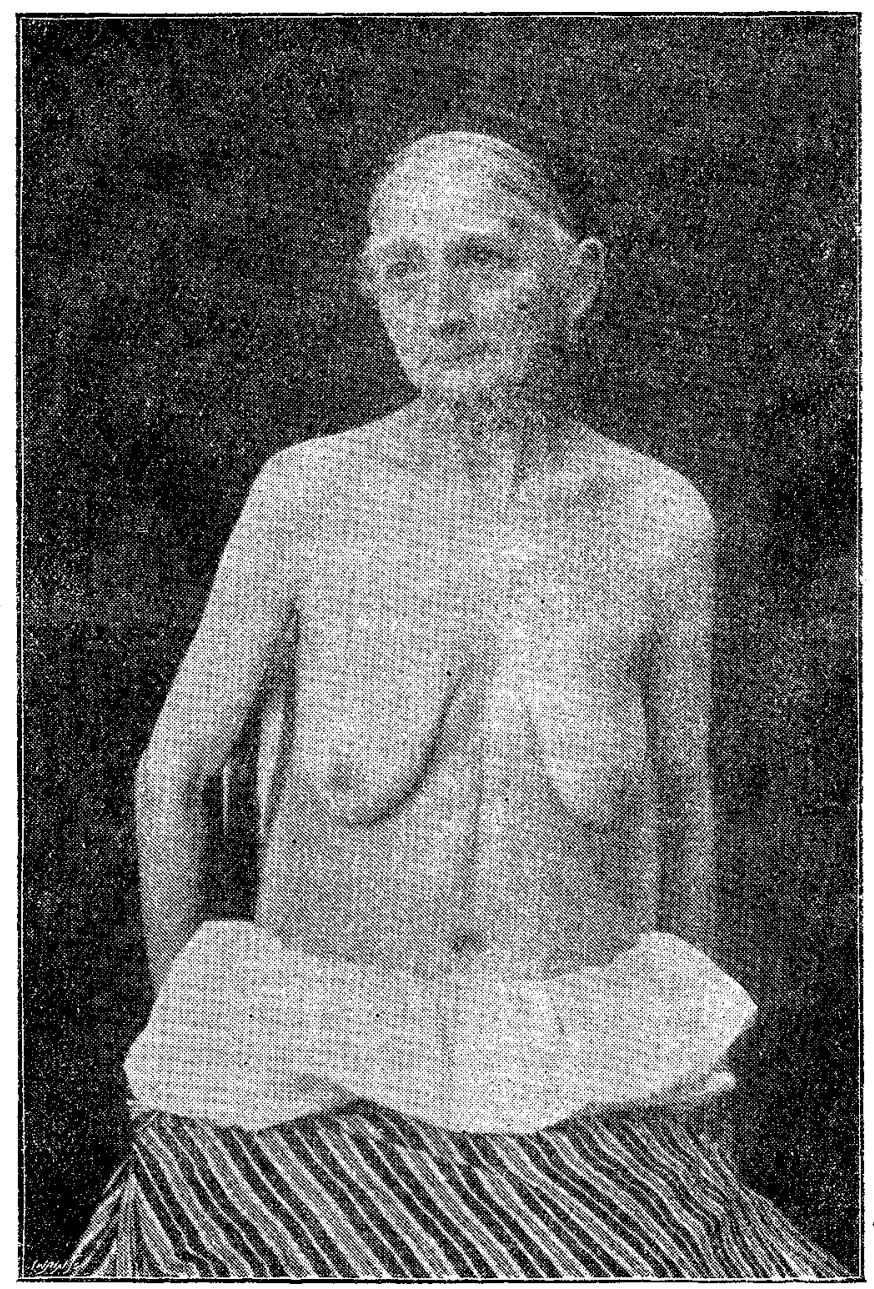

Photograph of patient taken on Nov. 22nd, 1897, eleven weeks after the removal of her stomach

Shortly before vomiting she complained of bitterness and a taste of bile in her mouth. On Oct. 2nd and Oct. 4th she vomited again about 200 c.c. (7 fluid ounces) of yellowish masses, free from fæcal odour, about an hour after taking food; some portions of egg were floating unchanged in the vomited matter. On Oct. 8th about 150 c.c. ( $5 \frac{1}{4}$ fluid ounces) of mucous fluid, yellowish but not floccalent, which had been romited three-quarters of an hour 
after taking milk and egg, were sent to the chemical laboratory of the Medical Klinik. According to the chemical report annexed to the history of the case, the vomited matter tad an acid reaction, contained lactic acid, but no free hydrochloric acid, and evidently possessed the qualities of the ferment trypsin. Biliary acids and bile colouring matter were also present. (The prescription of pepsin and hydrochloric acid had been discontinued for some time.) The patient (see Fig. 2) left her bed for the first time on Oct. 11th. On 0ct. 25th she felt herself extremely well in all respects; she had by this time been taking short walks in the garden for some days. Her weight increased continually in a gratifying manner. Unfortunately the precise recording of the weight was discontinued as the patient improved, but she must have gained at least 2 kilos. ( $4 \frac{1}{2} l b$.) up to Oct. 5th, on which day she was first weighed after the operation, the length of time for this increase being therefore about a month. In the -ensuing week her weight rose from 33.6 kilos. to 33.75 kilos. (from $74 \mathrm{lb}$. to $74 \frac{1}{4} \mathrm{lb}$.). A week later it reached 35.26 kilos. $\left(77 \frac{1}{2} \mathrm{lb}\right.$ ), and to.day (Oct. 30th) it has risen to exactly $: 36$ kilos. $(791 \mathrm{lb}$.). On the whole she has therefore gained in weight about 44 kilos. ( $9 \frac{1}{2} \mathrm{lb}$.) since the operation, that is in about two months. ${ }^{2}$

I have now to enter into details on a technical point. Lingenbuch remarks ${ }^{3}$ with reference to his cases of gastrectomy: "Neither of our two resections of the stomach were absolutely complete. Such an operation would be hardly practicable on account of the relations of the cardiac portion which, moreover, like the head of the humerus, has its anatomical and its surgical neck. But having regard to these considerations our $t$ wo operations may be correctly described as total resections of the stomach, for in both of them as much was taken away as appeared at all possible from a practical point of view." The demarcation between the cesophagus and the cardia is so sharply defined by the transition from -squamous to cylinder epithelium that there cannot be two opinions about it. The microscopical examination of the cardiac margin of the excised stomach, conducted by Professor wibbert, showed incontrovertibly that in the present case the resection involved the osophagus. And yet I must admit that after the operation was completed it was not quite intelligible to me on anatomical grounds how it was that 1 obtained comparatively easy access for suturing the csophagus ; in fact, I pulled it downwards with considerable force towards the stomach whereby the portion of it below the diaphragm was made materially longer. I discussed this subject with anatomists who explained that it was a well - known circumstance that the portion of the oesophagus below the diaphragm, which is normally about 3 centimetres ( $1 \frac{1}{4}$ in.) in length, can be considerably increased by traction, and by some experiments on the dead body I was able to satisfy myself that the - wsophagus is capable of being moved lengthwise in the foramen by which it traverses the diaphragm. After the removal of the Wölfler's clamps the cesophagus in our case was strongly retracted upwards. Perhaps also the weight of the gastric tumour had by its long-continued traction contributed to the lengthening of the sub-diaphragmatic portion of the cesophagus.

In selecting the patient's dietary I had principally to keep in mind the functions of which she had been deprived by the complete removal of her stomach. Of course it was some encouragement to me to feel that in the present case the extension of the cancer had already reduced the functions of the stomach to a minimum, if it had not in fact destroyed them altogether, and the patient's recovery provided an instance of an excellent compensation for the loss. But even thongh the stomach has henceforth and for ever lost the time-honoured halo of glory by which it was distinguished as being the chief organ of digestion according to modern physiology, its functions will always be of the utmost importance from a physical and chemical point of view, neither is there any prospect of its owner being quite able to do without it. To begin with, the stomach is of great importance as a reservoir for receiving the food. In the next place its mechanical action has the effect of thoroughly mixing its contents with the gastric juice, a secretion containing free hydrochloric acid and pepsin, the latter of which has the

${ }^{2}$ On Nov. 20th the patient was still in the Surgical Klinik for the purpose of further chemical and physiological investigations. She then ielt quite well, was out of bed and at work all day long, took with few axceptions the ordinary diet of the patients, and has gained 500 grammes (about 180z.) in weight since she was shown at Olten, the total increase , 3ince the operation being therefore close on 5 kilos. (11 lb.). 3 Deutsche Medicinische Wochenschrift, 1894, p. 969. power of breaking up and dissolving a portion of the solid albumin of the food and of converting it into the so-called albumoses and peptones. The hydrochloric acid of the stomach is supposed to protect the intestine from bacterial infection and to exert a restraining action upon fermentation and putrefaction in the intestine. A certain amount of absorptive power is also attributed to the stomach.

I will now proceed to consider the conditions which resulted in consequence of each and all of these functions of the stomach being no longer in operation during and since the recovery of our patient. I naturally endeavoured to make up for the absence of the reservoir accommodation of the stomach by giving reduced quantities of food at shorter intervals than usual, so that as long as the patient took proper care she did not suffer from troubles due to this cause. Some few times it seemed to me that vomiting was caused by greatly overloading the digestive tract with a quantity of food amounting to or exceeding 300 c.c. ( $10 \frac{1}{2}$ fluid ounces) all at once. There was, however, another matter of more consequence - namely, that I did not first sufficiently take account of the fact that the stomach, in addition to being a reservoir, adjusts the temperature of the food. As in the after-treatment of other laparotomies I allowed cold tea and milk to be given during the days immediately following the operation. The attacks of diarrhcea and the slight increases of temperature in the course of these days may with the greatest probability be ascribed to enteritis caused in that way. Bearing in mind the absence of the mechanical action of the stomach, dietary articles were selected which pass out of the stomach as easily and quickly as possible, irrespective of its state of functional activity. From this point of view fluid foods are obviously the best. In the first week we confined ourselves strictly to those in the form of milk, milk with brandy, soup (bouillon), soup with egg, and such like. In the second week the patient took without inconvenience minced meat, thick gruel ("breiige Mehlspeisen"), and 100 grammes ( $3 \frac{1}{2}$ fluid ounces) of Malaga in the course of the day. In the third week she was able to take sausage and fowl and at a later period even chops, roast veal, and baker's rolls quite well. If her powers of mastication had been better I would at the last have permitted her to have the full allowance for a patient, but unfortunately she possessed only one tooth and that was a decayed stump. She usually took her food at intervals of from two to three hours. The daily quantity consumed consisted on an average of about a litre (35 fluid ounces) of milk, two eggs, from 100 to 150 grammes (from 4 oz. to $6 \mathrm{oz}$.) of groats, 200 grammes $(7 \mathrm{oz}$.) of meat, 200 grammes of gruel made with oatmeal or barley, one glass (? cup) of tea, and generally two rolls with 15 grammes ( $\frac{1}{2} \mathrm{oz}$.) of butter.

I was especially apprehensive of the effect which the absence of the chemical functions of the stomach would produce on the patient's system. Fats and carbohydrates are but little affected by the gastric juice itself; they are dealt with almost exclusively by the intestinal digestion, but the case is the very reverse with the albumin and the albuminous bodies contained in the food, for it is the stomach that acts on them. At the outset I naturally hoped to make up in some degree for the absence of the gastric ferment by the administration of hydrochloric acid and pepsin as ordinarily prepared, not reflecting that in the intestine the hydrochloric acid would be immediately neutralised by the alkaline ferment of the pancreas and that pepsin in an alkaline solution is inert. I however discontinued this treatment very soon. In the course of the patient's recovery I was able to make the very gratifying observation that she obtained all the benefit of the albuminous constituents of her food, notwithstanding the absence of hydrochloric acid and pepsin. The analyses of the frees and urine, which were made every day in the chenaical laboratory of the Medical Klinik in Zürich by Dr. Wroblewski, showed a remarkably small quantity of nitrogen, thereby indicating a very abundant absorption of albumin moreover, the assimilation of carbo-bydrates proved to be normal, as was to be expected. During the last few weeks the fat in the frces was somewhat increased in amount, which could be easily accounted for by the richness of the patient's diet. Biliary acids were also recognised in the fæces. De Filippi in his investigations on metabolism in the dog after extirpation of the stomach refers to a deficiency of biliary acids as the only abnormality in the fæces. This 
fact had been already mentioned by Ogata, who ascribed the deficiency of biliary acids to the absence of bydrochlonic acid, the consequence being that the taurocholic acid was not set free. In addition to these chemical analyses I bave had the fæces examined microscopically, the troublesome task having been most kindly undertaken by Dr. Habel. His report, which was based on a series of continuous observations, was as follows: The fæces were always of a firm consistence and well monlded, pale yellow in colour, and homo. geneous in texture. On microscopical examination there were found tolerably numerous fat globales, numerous acicular fatty crystals (a normal condition with a milk diet), and occasional undigested portions of vegetables, but no undigested muscle fibres or connective tissue fibres; there were also numerous crystals of triple phosphate. Bacteria were not abnormally numerous. Muscle fibres or connective tissue fibres were not found even when an experiment was made by giving the patient stringy boiled meat. The general result is that not the slightest deviation from the normal condition was revealed by the microscopical examination of the fæces. When I further recall to mind the fact in the patient's history that she has increased in weight by close on 5 kilos. (11 lb.) since the operation everyone will be convinced that there may be normal assimilation of the albuminous principles of the food notwithstanding the absence of the stomach without my presenting a full and precise table of the aralytical determinations of the metabolic process.

It is the trypsin of the pancreatic ferment which possesses such a power of dissolving proteids as to render pepsin digestion entirely superfluous. This observation is quite in accordance with the results of the above - mentioned experiments on animals made by Kaiser, Pachon, Carvallo, and de Filippi, whose dogs showed no changes in their metabolism notwithstanding the absence of their stomachs. The experiment of Czerny and Kaiser, whose dog however retained the cardiac portion of its stomach, is quite conclusive, as are also the experiments of Ludwig and Ogata who were able to nourish dogs sufficiently well on fowl's eggs beaten up and minced meat, which were injected into a duodenal fistula withont passing through the stomach. Ogata's explanation which his observations bear out is shortly this, that albuminons bodies, articles of food, and bciled connective tissue can be changed and prepared for absorption by the small intestine alone just in the same manner as by the combined operation of the stomach and the small intestine. If, however, the connective tissue introduced into the pylorus was not boiled but raw it was voided by the rectum in from six to eight hours after ingestion; the gelatin-producing fibres retained their shape perfectly and could be dissolved to a jelly by boiling. ${ }^{5}$ The result was always the same whether the connective tissue was administered alone or mixed with eggs and muscle fibres. Accordingly in freces derived from meat there was always found an abundant confused mass of fine fibres such as ordinarily occur among the muscular bundles.

In recent literature there are also recorded a few cases of jejunostomy in the human subject in which uniformity in the assimilation and excretion of nitrogen could be maintained for a considerable time. Friedländer ${ }^{6}$ injected both soluble and insoluble forms of albumen directly into a loop of the small intestine of dogs, killed the animals after four hours, and examined the contents of the loop of intestine. The greater part of the egg albumen and the serum albumin was already absorbed as well as that of the alkali-albuminate and the albumoses.

The possibility of doing without the function of digestion as it is conducted in the stomach is also evident from many clinical observations. For instance, Ewald and Einborn showed before the Hufeland Society cases in which complete and long-continued non-secretion of gastric juice was demonstrated. Von Noorden ${ }^{7}$ has shown by investigations of the phenomena of nutrition that patients in whom the power of secreting hydrochloric acid in the stomach was completely in abeyance and in whom there was consequently no pepsin digestion were nevertheless enabled to derive full benefit from their food just as if their stomachs bad been in the ordinary condition. No more than a normal proportion of the considerable quantities of albumin and fat which they took was lost in the fæces.

Archir für Anatomie und Physiologie (Physiologische Abtheilung) 1883, pp. $98-104$.

$$
\text { Ceitschrift für Biologie, Bd. xxxili., N.F., Bd. xv. }
$$

Von Noorden: Lehrbuch der Pathologie des Stoff wechiels, 1893, and Zeitschrift für Klinische Medicin, rol. xrii.
Morit ${ }^{8}$ has made an extremely instructive investiga. tion of the phenomena of nutrition in the case of a patient who in addition to loss of the faculty of gastric digestion, due to absolute non-secretion of bydrochloric acid and pepsin, suffered from the embarrassirg complication of chronic intestinal catarrh, the result being that the focd which was taken was hurried through the entire digestive tract in an average period of five hours. The patient, however, was well sustained by the fat and carbohydrates of his food axd there was also a considerablo amonnt of albumin absorbed, although some of it was lost.

Moritz endeavoured to elucidate the conditions of normas gastric djgestion in the $\mathrm{dog}$ by means of a duoderal fistula which was situated close to the stomach and through which the contents of the stomach as they escaped from the pylorus were intercepted and further examined. By these investigations it was found that with a great proportion of the food the ouly $\in$ ffect of the chemical action of the stomach was to convert it into a slippery pultaceous mass which was then sent through the pylorus. When the dcg was fed on minced raw meat 58 per cent. of the quanti'y was discharged into the intestine in an undissolved condition. The pylorns even allowed small pieces of sausage to pass through, although they were retained for a considerable time. Moreover, the absence of the milk curdling ferment does not create any notable derangements. It is not recessary to suppose that it is replaced by an acid fermentation for the intestinal canal possesses a milk.curdling ferment of its own. Roberts, Harris, and Gow liave drawn attention to the fact that al the pancreatic extracts coagulate milk and the mucous membrane of the small intestine seems to secrete a ferment of this kind throughout its who'e $\epsilon$ xtent. ${ }^{9}$

Our patient supplies a valuable contribution to the solution of the question whether the hydrochloric acid of the stomach has or bas not an influence on the process of putrefaction in the intestive. Her arine and fæces were examined for putrefaction products regularly every day and I al ways received from the chemical laboratory the report that skatoxyl and indoxyl were either altogether absent from the urine or were present only in traces. It was only on three consecutive days that the analyses showed the proportion of indosyl and skatoxyl to be increased. The proportion of indol and skatol in the frees was not abnormal. This result agrees perfectly with that cbtaired by von Noorden in his researches. He made forty-six separate determinations in the case of eleven patients who had almost completely lost the faculty of secreting bydrochloric acid ard he was so far from confirming the researches of Kast and Wasbutzikis that he met with only five instances in which the products of decomposition of albumin derived from the intestine and appearing in the urine as ethereal sulphates were greater in amount than might have been expected with patients whose stomachs were healthy. Our patient, as the outcome or numerous experiments prolonged for many weeks, supports the conclusion of von Noorden (in opposition to recent researches in Bumann's laboratory), that deficlency of bydrochloric acid in the stomach exercises no influence or the progress of the natural putrefactive processes in the intestine.

The antiseptic action of the gastric juice upon various pathegenic organisms, although proved by a series of beautiful researches, must not be over-estimated. Falk and Frank- found that the gastric juice destroyed antbraz bacilli but not the spores which the bacilli contain. The tubercle bacillus, however, was not cestroyed by the gastric juice. Like Falk, Frank also comes to the conclusion that the digestive juices do not oppose any general or active resistance to the attacks of pathogenic organisms. Quite recent incuiries also lead as to suppose that the absorptive activity of the stomach is much less than we have hitherto keen accustomed to believe. In experiments made on dogs in which duodenal fistula were established von Mering ${ }^{10}$ and Morit ${ }^{11}$ were able to prove that the whole of the water which was given to the animals to drink left the stomach again by way of the pylorus in a relatively short time -generally within from swenty to thirty minutes - without its amount being reduced by absorption into the stomach; on the contrary, in many experiments a few extra cubic centimetres were collected if the stomach happened to be secreting fluid. In one of Moritz's experiments of

8 Münchener Medirinische Wochenschrift, 1895, No. 49.

10 Verhandlungen des Congressea fir junere Medicin, Twelfth Congress, 1893, p. 473 . 


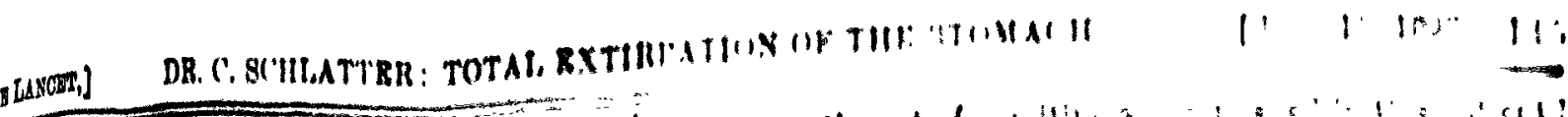

with meat only 5 per cont. of what wan iaken

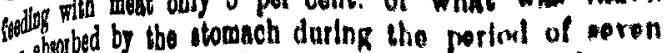
as abos thith the expertment wn continuerl. In an fout tot which mill 116 grammas of mirol ramoln and

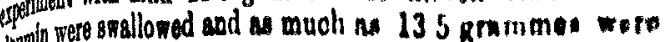

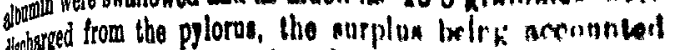
whot the fact that the secretion of the mucous memingann

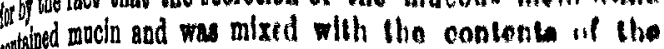

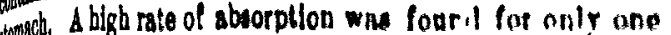

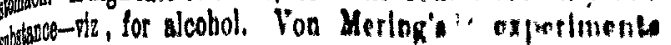
alus that an sbondant flow of water Into the stominch lakes uesimultaneondy with the sbeorptlon of alcohol. The mote

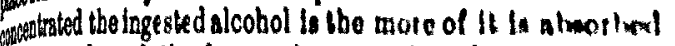
in the stomech, and the largat the quandliy of walas whirh

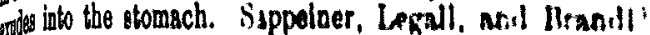
Werrad thast the absorption of other sohelasocen was po

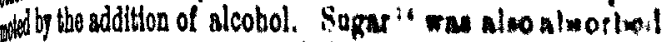
inderate gasotity, poptone and derito to a mall ex cont.

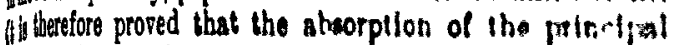

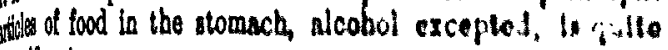
ingidisant.

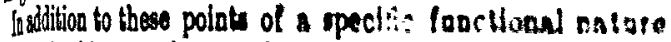

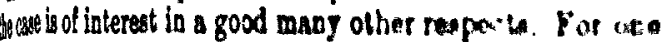
ding the gaestion presents livelf - Is there allof pomo:al (thastomsch a chapge in the rate at which lood pauce

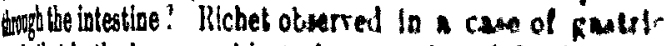

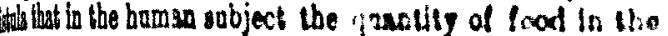

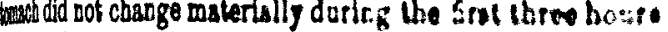
tot that atter that almost everythicg was expelied in tho

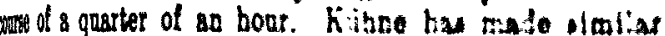
derations both on patieols and in don" Arcordice w the inestigators the emplyite of the ulomach in the

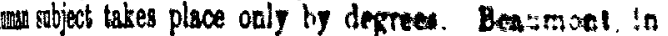

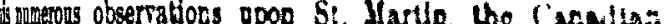
tome, fond that in general the elomach ras orfy ot ton one and a ball to ire and a ha: bara thes times sccordiog $\omega$ the rayte talure of

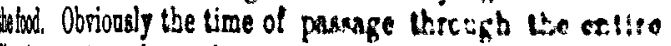

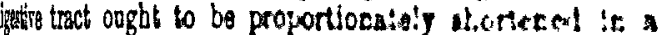

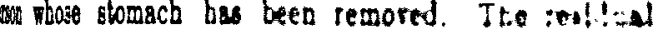

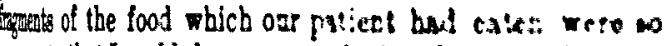

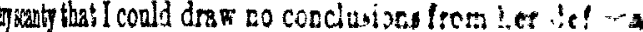
ong wich took place at the mos: orce thy nt! cl:e

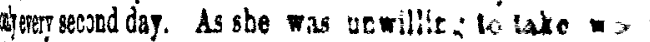
I lad recourse prorisioraliy is as exjastect:

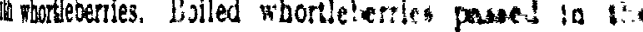

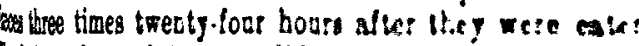

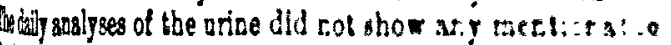

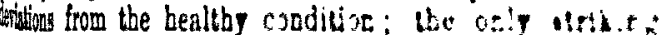

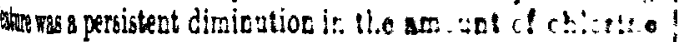
anded, recorring in every daily clist:. The fopos:t t : !

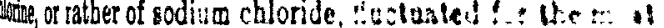
at betreen 0.6 and $0 \delta$ per cent, the sealient a.t.

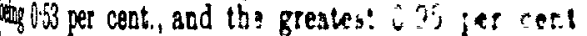
wepe the quantiti of salt coctained is lle tood has a is

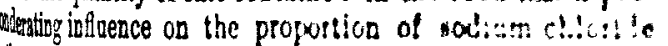

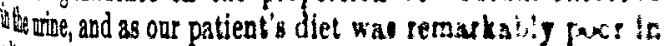
4ascompared with ordinary fare, I do sol recticre to cha the conclusions from these observatlot:s.

the patient's clinical bistory mates mertion of $f(c)$

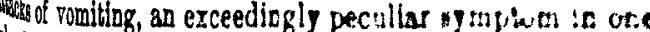
fin did not possess a stomach, and rery discotcerting to the mo are inclined to ascribe to the anil.peristitile moro ats of the stomach wall an essential part in the ar: Fonitiog, For gome time after the operallon the : bleot andy regurgitation of food now and then; vie ron

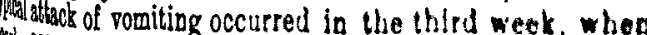
a f 300.c. (10t flaid ounces) of lood In a pulpy con.

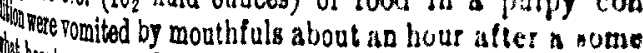
st bearty meal. On another occusion the romleing atombable to a feoling of revulsion wblch the experienced

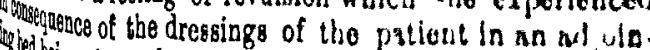
hed foing changed. On chemical examination $[C 4 \mathrm{c}: \mathrm{c}$ 34 tored romit, which was acld, wore neutrallower ip 4hiof decinormal caustic soda solution. It conlatnoil Whic aile acids, and bile plgment, but no freo bydro

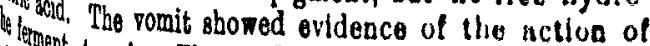
whithe trppsin. The conducting tube of the ominil

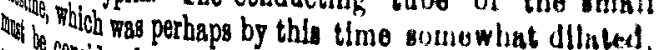

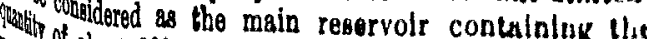
soniced, about 300 c.c. (10) fluid ouncen) which wa

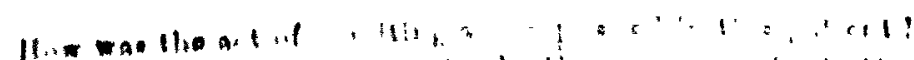

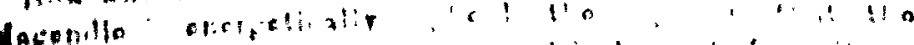

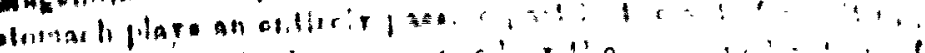

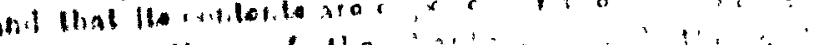

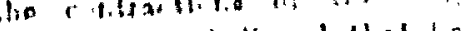

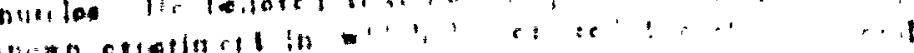

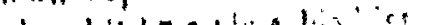
(line

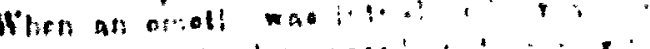

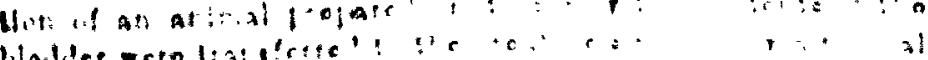

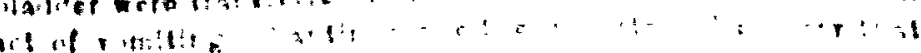

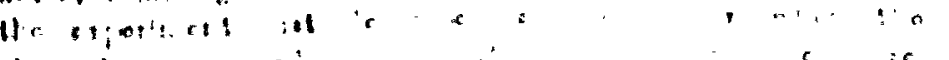

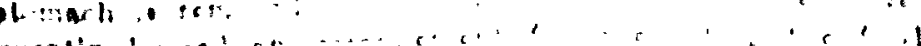
quentiy irsice: as

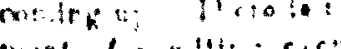


fact had been already mentioned by Ogata, who ascribed the deficiency of biliary acids to the absence of bydrochloric acid, the consequence being that the taurocbolic acid was not set free. In addition to these chemical analyses I bave had the frces examined microscopically, the troublesome task having been most kindly undertaken by Dr. Habel. His report, which was based on a series of continuous observations, was as follows: The fæces were always of a firm consistence and well monlded, pale yellow in colour, and homo. geneous in texture. On microscopical examination there were found tolerably numerous fat globules, numerous acicular fatty crystals (a normal condition with a milk diet), and occasional unojigested portions of vegetables, but no undigested muscle fibres or connective tissue fibres; there were also numerous crystals of triple phosphate. Bacteria were not abnormally numerous. Muscle fibres or connective tissue fhres were not found even when an experiment was

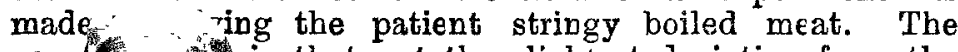
gened (1) is that not the slightest deviation from the norn $\quad$ a $\mathrm{n}$ was revealed by the microscopical examination : 3 ss. When I further recall to mind the fact close cony albur absen abser precis metal

It i such. diges bistory that she has increased in

$11 \mathrm{lb}$.) since the operation every here may be normal assimila . I o be 43. biples of the food notwith the araly tical determit

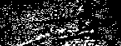

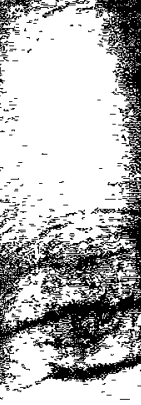
the aralytical determin

of the pancreatio ferment dissolving proteids as $t$ superfluous. This obs the results of the nals made by Kaiser pse dogs showed $n$ tanding the absend zerny and Kaise portion of its st xperiments of dogs sufficie od meat, wh hont passin which his iminous te can $\mathrm{b}$ inter
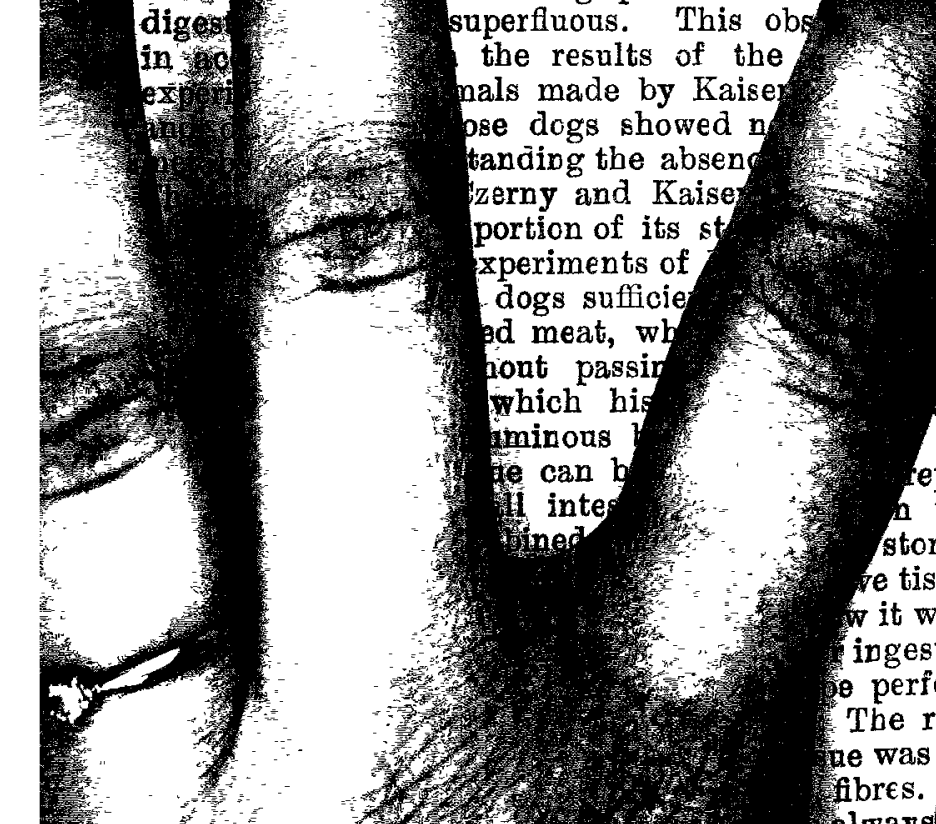

sin aite oned ballo, their aache. bwever conclata who 's eggs into into a

out is food. and epared for Moritz ${ }^{8}$ has made an extremely instructive invest tion of the phenomena of nutrition in the case of patient who in addition to loss of the faculty of gas digestion, due to absolute non-secretion of bydrochl acid and pepsin, suffered from the embarrassing a plication of chronic intestinal catarrh, the result be that the focd which was taken was hurried through entire digestive tract in an average period of five ho The patient, however, was well sustained by the fat carbohydrates of his food and there was also a considera amonnt of albumin absorbed, althongh some of it was lost

Moritz endeavoured to elucidate the conditions of non gastric digestion in the dog by means of a duodenal fist which was situated close to the stomach and through wh the contents of the stomach as they escaped from pylorus were intercepted and further examined. By th investigations it was found that with a great propor of the food the only effect of the chemical action the stomach was to convert it into a slippery pultace mass which was then sent through the pylorus. W the dog was fed on minced raw meat 58 per ce of the quantily was discharged into the intestine in undissolved condition. The pylorus even allowed sn pieces of sausage to pass through, although they retained for a considerable time. Moreover, the absence the milk.curdling ferment does not create any nota derangements. It is not necessary to appose that il replaced by an acid fermentation for the intestinal ca possesses a milk.curdling ferment of its own. Robe Harris, and Gow lave drawn attention to the fact that the pancreatic extracts coagulate milk and the muc membrane of the small intestine seems to secrete a ferm of this kind throughont its whole $\in$ xtent.

Our patient supplies a valuable contribution to solution of the question whether the hydrochloric acid the stomach has or has not an influence on the proc of putrefaction in the intestive. Her urine and fæces w examined for putrefaction products regularly every day a I always received from the chemical laboratory the rep that skatoxyl and indoxyl were either altogether absent fr the urine or were present only in traces. It was only on th consecutive days that the analyses showed the proportion indoxyl and skatoxyl to be increased. The proportion ind and skatol in the fæces was not abnormal.

agrees perfectly with that obtaired by von Nocrden earches. He made forty-six separate determinati case of eleven patients who had almost complet faculty of secreting bydrochloric acid ard he was $m$ confirming the researches of Kast and Wasbutz met with only five instances in which the products position of albumin derived from the intestine fing in the urine as ethereal sulphates were greater nt than might have been expected with patients wh achs were healthy. Our patient, as the outcome grous experiments prolonged for many weeks, suppc conclusion of von Noorden (in opposition to reo arches in Bumann's laboratory), that deficlency rochloric acid in the stomach $\epsilon$ xercises no influence progress of the natural putrefactive processes in stine.

The antiseptic action of the gastric jaice upon vari thcgenic organisms, although proved by a series autiful researches, must not be over-estimated. F id Frank. found that the gastric juice destroyed anth acilli but not the spores which the bacilli contain. abercle bacillus, however, was not cestroyed by the gas nice. Like Falk, Frank also comes to the conclusion t the digestive juices do not oppose any general or aci resistance to the attacks of pathogenic organisms. O recent inquiries also lead us to suppose that the absorpl activity of the stomach is much less than we $h$ hitherto been accustomed to believe. In experiments $\mathrm{m}$ on dogs in which duodenal fistulæ were established. Mering ${ }^{10}$ and Moril ${ }^{11}$ were able to prove that the whol the water which was given to the animals to drink left stomach again by way of the pylorus in a relatively short $t$ - generally within from twenty to thirty minutes-without amount being reduced by absorption into the stomach the contrary, in many experiments a few extra cu centimetres were collected if the stomach happered be secreting fluid. In one of Morikz's experiments

8 Münchener Medicinische Wocbenschrift, 1895, No. 49.

9 Gamgee, $p .463$.
10 Verhandlungen des Congresses für invere Medicin, Trelfth 10 Verhandlungen des Congresses fur innere Medid
gress, 1893, p. 473 . 
Seeding with meat only 5 per cent. of what was taken was absorbed by the stomach during the period of seven bours for which the experiment was continued. In an experiment with milk 116 grammes of mixed casein and albumin were swallowed and as much as 13.5 grammes were discharged from the pylorus, the surplus being accounted for by the fact that the secretion of the mucous membrane contained mucin and was mixed with the contents of the stomach. A high rate of absorption was found for only one substance-viz, for alcohol. Von Mering's ${ }^{12}$ experiments prove that an abundant flow of water into the stomach takes place simultaneously with the absorption of alcohol. The more concentrated the ingested alcohol is the more of it is absorbed in the stomach, and the larger the quantity of water which exudes into the stomach. Sappeiner, Legall, and Brandl'13 observed that the absorption of other substances was promoted by the addition of alcohol. Sugar ${ }^{14}$ was also absorbed in moderate quantity, peptone and dextrin to a small extent. in $t$ is therefore proved that the absorption of the principal articles of food in the stomach, alcohol excepted, is quite insignificant.

In addition to these points of a specific functional nature the case is of interest in a good many other respects. For one thing the question presents itself-Is there after removal of the stomach a change in the rate at which food passes through the intestine? Richet observed in a case of gastric iistula that in the human subject the quantity of food in the stomach did not change materially during the first three hours out that after that almost everything was expelled in the course of a quarter of an hour. Kühne has made similar observations both on patients and on dogs. According to wother investigators the emptying of the stomach in the suman subject takes place only by degrees. Beaumont, in yis numerous observations upon St. Martin, the Canadian hunter, found that in general the stomach was empty in from one and a half to five and a half hours aiter meal times according to the varying nature of she food. Obriously the time of passage through the entire digestive tract ought to be proportionately shortened in a person whose stomach has been removed. The residual fragments of the food which our patient had eaten were so very scanty that I could draw no conclusions from her defæcasions, which took place at the most once a day and often only every second day. As she was unwilling to take wood sharcoal I had recourse provisionally to an experiment with whortleberries. Boiled whortleberries passed in the faces three times twenty-four hours after they were eaten. The daily analyses of the urine did not show any mentionable deviations from the healthy condition; the only striking feature was a persistent diminution in the amount of chlorine arcreted, recurring in every daily chart. The proportion of shlorine, or rather of sodium chloride, fluctuated for the most part between 0.6 and 0.8 per cent, the smallest amount Deing 0.53 per cent., and the greatest 0.95 per cent. As "nowerer the quantity of salt contained in the food has a preponderating influence on the proportion of sodium chloride in the urine, and as our patient's diet was remarkably poor in salt as compared with ordinary fare, I do not venture to draw inther conclusions from these observations.

The patient's clinical history makes mention of four attacks of vomiting, an exceedingly peculiar symptom in one who did not possess a stomach, and very disconcerting to whose who are inclined to ascribe to the anti-peristaltic movements of the stomach wall an essential part in the act of romiting. For some time after the operation the patient aad only regurgitation of food now and then; the first typical attack of vomiting occurred in the third week, when

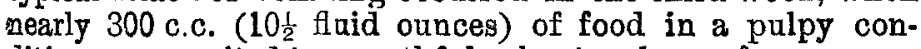
Jition were vomited by mouthfuls about an hour after a somewhat hearty meal. On another occasion the vomiting was attributable to a feeling of revulsion which she experienced in consequence of the dressings of the patient in an adjoining bed being changed. On chemical examination 100 c.c. of the filtered vomit, which was acid, were neutralised by 3.4 c.c. of decinormal caustic soda solution. It contained lactic acid, bile acids, and bile pigment, but no free hydrochloric acid. The vomit showed evidence of the action of the ferment trypsin. The conducting tube of the small intestine, which was perhaps by this time somewhat dilated, must be considered as the main reservoir containing the

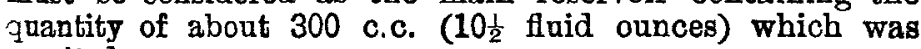
Fomited.

22
13 Loc. cit., p. 477 .

24 Hammarsten: Lehrbuch der Physiologischen Chemie, 1891, p. 158.
How was the act of vomiting accomplished in this patient? Magendie $e^{15}$ energetically upheld the opinion that the stomach plays an entirely passive part in the act of romiting, and that its contents are expelled by the combined action of the contractions of the diaphragm and the abdominal muscles. He believed that he had proved this by the wellknown experiment in which he excised the stomach and replaced it by a pig's bladder filled with water and united to the lower part of the cesophagus by a flexible coupling. When an emetic was introduced by a vein into the circulation of an animal prepared in this way the contents of the bladder were transferred to the creature's mouth by a normal act of vomiting. Santini made the important discovery that the experiment just described succeeds only when the stomach is removed together with the cardia and he subsequently devised an arrangement for preventing the food coming up. There is no difficulty in explaining the startingpoint of vomiting even in a person who has no stomach. Vomiting is a complicated operation associated with quite a number of phenomena of movement in the stomach, the œsophagus, the pharynx, the diaphragm, and the abdominal muscles. Such complicated movements can only be set a-going by the nervous centres. The centre for vomiting is acted upon reflexly not only by the stomach but by various other organs especially by those of digestion and by the pharynx, the cesophagus, and the intestine. In one of the attacks of vomiting already mentioned the reflex influence was purely mental, the exciting cause being an accidental feeling of revulsion; in the other cases it originated from the lower part of the cesophagus or from the small intestine and was perhaps due to the mechanical irritation of these parts by too liberal a supply of food.

The etiology of gastric tetanus is a subject of great interest both physiologically and clinically and may obviously be discussed in connexion with this patient's case. This condition was first described by Kussmaul, and subsequently by Gerhardt, Müller, and others; von Mering ${ }^{16}$ also observed the same combination of symptoms in dogs in which duodenal fistulæ were established. Milk was liberally supplied to the small intestine and was well absorbed by it, but in from three to eight days after the operation convulsive movements of the limbs and the facial muscles supervened, the animals' limbs became stiff so that they did not walk freely, they groaned, ground their teeth, showed sometimes palsy of a limb and as a regular thing a greatly increased reflex irritability; drowsiness with sighing respiration succeeded and they soon died. The cause of this gastric tetanus was supposed by von Mering to be the absence of the secretion of the mouth or the absence of a substance secreted by the stomach (hydrochloric acid, mucin, \&c..). In our case the absence of the entire gastric secretion has not up to the present time produced even one of these symptoms in the faintest degree. It must be admitted, however, that this is not an absolute disproof of the gastric origin of the disease, for as was remarked by von Mering, it is conceivable that the formation of the substance in question is of no consequence for the maintenance of life but that, on the other hand, life is endangered when the substance which would be formed under normal conditions is no longer returned to the circulation.

There still remain a number of interesting questions, principally of a chemico-physiological nature, some elncidation of which we hope to obtain through the medium of our patient; the time of observation has, however, been too short to justify me in entering on them at present. In fact, what precedes is to be accepted as a provisional communication, further observation and research being necessary before definite opinions can be arrived at.

The scientifically and practically important question whether the total removal of the stomach in the human subject is compatible with a continuance of life has with great probability been answered in the affirmative by the case which has now been briefly narrated. The stomach is essentially an organ for the protection of the intestine, mitigating or removing such properties of the food as might have an in jurious influence on the intestine. Provided that the food is of suitable quality the intestine is quite competent to perform the chemical work of the stomach.

Postscript by Dr. Schlatter of date Jan. 10th, 1898.-The patient still remains in the Zürich Surgical Clinic for the purpose of further chemical and physiological investigations. 
She feels perfectly well and is out of bed all day long, busily engaged in various employments. She takes with few exceptions the ordinary patients' dietary, consisting of farinaceous food (Mehlspeisen), meat, fruit, and vegetables such as beans, peas, \&c.; milk diet. however, is considered to be the most wholesome for her. Her wejght was found on Dec. $3 \mathrm{rd}$ and Dec. $17 \mathrm{th}, 189 \mathrm{~T}$, to be 37.5 kilos. ( $82 \frac{1}{2} \mathrm{lb}$ ) sa that she has gained in weight about 6 kilos. ( $13 \frac{1}{4} \mathrm{lb}$.) since the operation. On Dec, $23 \mathrm{rd}$ she was seized with severe angina (i.e., tonsillitis or sore-throat) and had an evening temperature of $39.8^{\circ} \mathrm{C}$. $\left(103.6^{\circ} \mathrm{F}.\right)$. This illness bad the effect of bringing down her weight to 37 kilos. (81: lb.) on Dec. 31st, 1897.

Zuirich.

\section{THE ACTION OF VERATRUM VIRIDE IN} $\Lambda$ CASE OF PUERPERAL ECLAMPSIA. ${ }^{1}$

BY JOHN GORDON, M.D. ABERD.,

ASSISTANT PHYSICIAN, ABERDEEN ROYAL INFIRMARY; ASBISTANT TO THE PIOFLISSOR OF MATERIA MRDICA, AHERDEEN JNIVERSTTY.

THE patient was a married woman, aged forty years, a multipara, whose previous confnements had been attended with no difficulty. The patient was seen on July $5 \mathrm{th}$, being then in the ninth month of pregnancy. The first indication of anything abnormal in her labour took place on the evening preceding the day on which the child was born. She had siuffered for years from what she defined as bilions headaches attended with severe sickness and occasionally fainting. What seemed to be one of her ordinary headaches was being undergone when about 6 P.M. her mother thought the patient had something like a fit. It lasted, however, only a few minutes. I was sent for at nine o'clock the same evening and found her complaining of severe headache which she alleged to be of her usual type. Her pulse was 120 and hard, the respirations were 22 per minute, the pupils were contracted, the tongue was furred, there was an offensive odour with the breath, and the legs and feet were swollen. I waited for one and a half hours because, in spite of her own idea that she had had no fit although she might have fainted, I suspected the possibility of puerperal eclampsia.

I was not sent for again till 530 next morning and was then told that she had had sereral attacks-at $1.30 \mathrm{~A} . \mathrm{M}_{\text {., }}$, at 4 A.M., and again at 5.30 A.M., after which she had lost consciousness. Only then the friends sent for me. When I arrived she was just passing into another fit which was severe, lasting for about five minutes. After the fit she was quite unconscious; there was a firm, strong pulse of 100 , the respirations were 28 , the pupils were contracted, the corneal reflex and other evidence of sensation being abolished, and the face was livid and puffy. I resolved at once to try veratrum viride, which had yielded such good results in the hands of Professor Stephenson some time previously. My efforts to obtain it from the druggists were, however, fruitless. I then took the liberty of asking Professor Stephenson for a supply, which he kindly consented to give and at the same time volunteered to come and see the case. From the time of my arrival till the coming of Professor Stephenson four other convulsive seizures took place, increasing in violence. Meantime vaginal examination revealed a rigid os of abont the size of a shilling. Uterine contractions took place at irregular intervals between the fits. Immediately on the arrival of Professor Stephenson, at 8.15 A M., a 5 minim hypodermic injection of the fluid extract of veratrum viride was given in the foxearm. At this time the palse varied in rate from 92 to 100 per minute and was hard, firm, and bounding. The temperature talcen immediately after a fit was $100^{\circ} \mathrm{F}$. The skin was moist and sensation was still absent. At 830 A.M. the pulse was 84 , softer in character, with less of the firm. bounding nature and slightly unequal in the value of its beats. The skin was more moist. The patient moaned a good deal; stimulation of the refiexes gave no result. At $8.35 \mathrm{~A} . \mathrm{M}$. the pulse was 72 , and at $8.40 \mathrm{~A} . \mathrm{Mr}$. it had slowed to 54 . The refiex of the cornea was now apparent and the patient raised her hand to ward off $m y$ inger from the eye. At this

1 A paper read at a meeting of the Aberdeen Medico-Chirurgical Society on Dec. 2nd, 1897. time she made efforts at vomiting and the skin became. covered with moisture. At 8.50 A.M. the pulse was still 54 soft and compressible and vomiting took place, which was bilious in appearance. At 9.5 A.M the pulse was $5 \mathrm{~L}$ and very soft in character. A considerable quantity of bile-stained mucus was conghed up and there were frequent attempts at vomiting. Uterine pains proceeded: the external os had dilated to $1 \frac{1}{2}$ inches; the internal os had the head engaged; and the external parts were moist and natural. At 9.10 A.M. the right ejeball was rolled downwards and inwards, the left also, but not so much as the right. The pulse now varied from 58 to 60 , and more evidence of consciousness was given in response to the touch. A large quantity of bilious-looking material was vomited and the skin was very moist. At 9.15 A.M. the pulse was 52 and the temperature was $99 \cdot 5^{\circ}$. At this time Professor Stephenson began to deliver the child. At $943 \mathrm{AM}$. the pulse was. 60 while the foot was being brought down. At 9.55 A.M the child was born; at $10.5 \mathrm{~A} . \mathrm{M}$. the placenta came away; there was no hæmorrbage and the uterus contracted well. At $10.15 \mathrm{~A} . \mathrm{M}$. the pulse was from 54 to 60 . the temperature was $100.4^{\circ}$, and the respirations were 28 . At 11.10 A.M. the plantar reflex was present, the pulse was 60 per minute and soft, the temperature was $998^{\circ}$, and the respira. tions were 24 ; there was less moaning with the breathing. and an appearance of downward pressure with respiration: strabismus of the right eye and the corneal reflex were present, the colour of the face and lips becoming more natural. At $415 \mathrm{P} . \mathrm{M}$. in the afternoen Professor Stephenson called and made the following note. "The patient had rested quietly since one o'clock; the breathing and colour were good; she resented the opening of the eyelids; took: four teaspoonfuls of brandy-and-water, responded to spoon, and swallowed naturally; resisted abdominal examination; there was slight moaning as if half conscious; the pulse was 56." I called at 9.15 and found the patient sleeping, breathing deeply and quietly; she resented any attempt to open the eyelids and said, peevishly, "Be quiet." The pulse was 60 and fuller and firmer than in the morning, the respirations were 16 , the temperature was. normal, and the lochia were about normal in quantity. The patient's colour was good. No vomiting or coughing of froth had taken place since 1 P.M. She became conscious about 10 P.M., asked a few questions, and then got mixed in her ideas. She soon fell asleep, however, and slept nearly all night. I found her awake at 1030 next morning and able to do what she was asked. The tongue was dirty and swollen and the breath had an offensive odour. The pulse was 80 , firm, strong, and steady ; the respirations were 20 ; the temperature in the month was $99.2^{\circ}$; the right eyeball rotated inwards and downwards; and she complained of headache and pain all over the body. The quantity of' urine passed during the night was $20 \mathrm{cz}$. At $5.50 \mathrm{P} . \mathrm{M}$. the pulse was 80 and the patient was sleeping. On the 8 th-that is, the second day after the birth-the pulse was 80 and the respirations were 20 ; the temperature was normal ; the eyes were strabismic and she complained of headache; the strabismus disappeared on the succeeding day. From this time onward the patient progressed steadily towards complete recovery. I may state that after the disappearance of the lochia examination of the urine showed a considerable quantity of albumin to be present. The patient has still traces of albumin in the urine as a recent examination shows. It may be useful to give a short description of veratrum viride as the drug is not specially well known. The dry rhizome and rootlets are the parts used. It is an American plant and inhabits swamps, moist meadows, and the banks of mountain streams. It is most abundant northward but reaches as far south as the Carolinas. It flowers from May to July and it is a moot point whether the rhizome should be collected in autumn or just before flowering time. It ought not to be used if it has been kept longer than a year as it deteriorates. The rhizome is from an inch to two inches in length by three-quarters of an inch in breadth, of a chocolate. brown colour externally, and is closely invested with numerous yellow, wrinkled rootlets an inch or two inches long. The rhizome bas a bitter, acrid taste, is inodorous, but produces sneezing when snuffed in powder form. The United States officinal preparations made from it are the liquid extract and the tincture. The dose of the liquid extract is from one to three minims and of the tincture from three to sis minims. Its chemical composition, given by Bullock, who frst discovered the alkaloids, was veratrine and veratroidine, both of them alkaloids, and a resin. It is somewhat more: 